\title{
The Radiation Degradation of Neutral Red Solution by $\gamma$-Ray
}

\author{
Xiu-Hua Liu, Yi Deng, Yin-Hang Zhou, Liang Xia, Lan-Lan Ding, Yu-Chuan Zhang \\ China Academy of Engineering Physics, Mianyang, China \\ Email: liuxiuhuajulia@yahoo.com.cn
}

Received May 15, 2012; revised June 25, 2012; accepted July 8, 2012

\begin{abstract}
Neutral red is kind of biologic colourant and acidity-basicity indicator. Radiation degradation of neutral red in aqueous solution was done by $\gamma$-ray. The removal rate of chemical oxygen demand, total organic carbon, chroma and the changing of $\mathrm{pH}$ value were studied under various conditions. With the increase of absorbed doses, the chemical oxygen demand and chroma decreased conspicuously. The absorbed dose rate has little effect on the degradation of neutral red. When the absorbed doses are the same, the chemical oxygen demand and chroma decreased more obviously with the increase of neutral red concentration. Weak basic condition and proper $\mathrm{H}_{2} \mathrm{O}_{2}$ addiation are propitious to removal of chemical oxygen demand of neutral red.
\end{abstract}

Keywords: $\gamma$-Ray; Irradiation; Neutral Red; Degradation

\section{Introduction}

For the rapid development of dyestuff industry, the dyeing wastewater is recognized as one of the intractable industrial organic wastewater for its large amount discharge, complex composition with toxicity and deep color [1]. Neutral red is an important coloring agent for its aqueous solution in deep red. Neutral red is often used as linsey-woolsey coloring agent, biological stain and acid-base indicator. Therefore, neutral red is also an important composition in dyeing wastewater.

Ionizing radiation seems to be an effective technology for the degradation of organic pollutants. Relative researches show that irradiation can achieve the effective treatment of organophosphorus compounds, halogenated hydrocarbon, carboxymethylcellulose, etc. [2-8]. Radiation degradation can be performed at ambient temperature and for large-scale treatment. Since the $\gamma$-ray has higher penetration, radiation degradation of neutral red in aqueous solution was done by $\gamma$-ray. The removal rate of COD, TOC, Chroma and the changing of $\mathrm{pH}$ value were studied under various conditions. The effect of absorbed dose rate, absorbed dose and $\mathrm{H}_{2} \mathrm{O}_{2}$ content on degradation efficiency of neutral red has been obtained.

\section{Experiment Method}

\subsection{Irradiation Method of $\boldsymbol{\gamma}$-Ray}

The radiation degradation of neutral red was done by a ${ }^{60} \mathrm{Co}-\gamma$-source with an activity of $230 \mathrm{kCi}$ (average energy of $1.25 \mathrm{MeV}$ ). Neutral red solution was irradiated in
$100 \mathrm{~mL}$ colorimetric glass vessels at certain dose rates. Absorbed dose was controlled by irradiated time. Every colorimetric vessel contained $55 \mathrm{~mL}$ neutral red solution. The absorption dose was calibrated by silver dichromate stoichiometric method (Chinese National Standard: JJG 1028-91). All experiments were performed at ambient temperatures.

\subsection{Analytical Method}

Several main indices of neutral red solution were quantitatively measured before and after irradiation. Chemical oxygen demand (COD) was measured by bichromate method (Chinese National Standard: GB 11914-89). Chroma was determined by diluted multiple method (Chinese National Standard: GB 11903-89). Total organic carbon (Chinese National Standard: TOC) and total inorganic carbon (TIC) were measured by OI Analytical $1030 \mathrm{C}$ Aurora Combustion Total Organic Carbon Analyzer according to nondispersive infrared absorption method (Chinese National Standard: HJ 501-2009). The pH value was determined by Mettler Toledo SG2 pH meter according to glass electrode method (Chinese National Standard: GB 6920-86). UV-Vis spectra of neutral red solution was carried out by a PE Lamda 12 UV-Vis spectrophotometer.

\section{Result and Discussion}

\subsection{The Effect of Absorbed Dose}

Neutral red solutions with concentration at $10 \mathrm{mg} / \mathrm{L}, 28.9$ 
$\mathrm{mg} / \mathrm{L}, 60 \mathrm{mg} / \mathrm{L}$ were irradiated for different doses from 0 to $20 \mathrm{kGy}$ at $74.68 \mathrm{~Gy} / \mathrm{min}$, in accordance with different concentrations. A little precipitation produced after radiation. The evolution of $\mathrm{pH}$ values, COD contents and Chroma of superstratum limpid liquid are showed in Figure 1. After irradiation, $\mathrm{COD}$ and $\mathrm{pH}$ value decreased rapidly. $\mathrm{pH}$ value decreased more obviously with the increase of absorbed doses, indicating that there is at least an acidic compound produced during the radiation degradation of neutral red.

COD of neutral red solutions decreased gradually with the increase of absorbed dose. For the solutions with the concentrations at $10 \mathrm{mg} / \mathrm{L}, 28.9 \mathrm{mg} / \mathrm{L}, 60 \mathrm{mg} / \mathrm{L}$, the COD decreased more than $57.6 \%$ at a dose of $5 \mathrm{kGy}$. When the absorbed doses are the same, the COD and

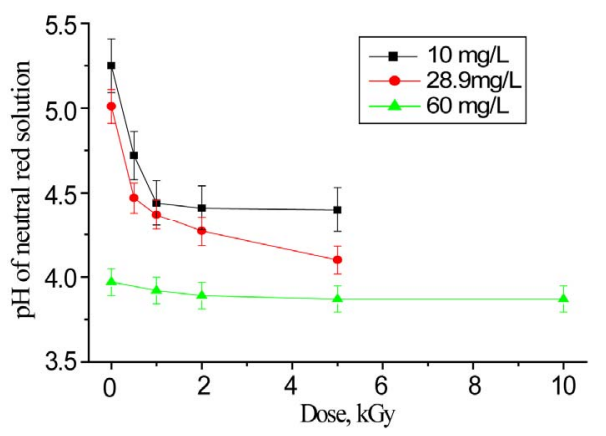

(a)

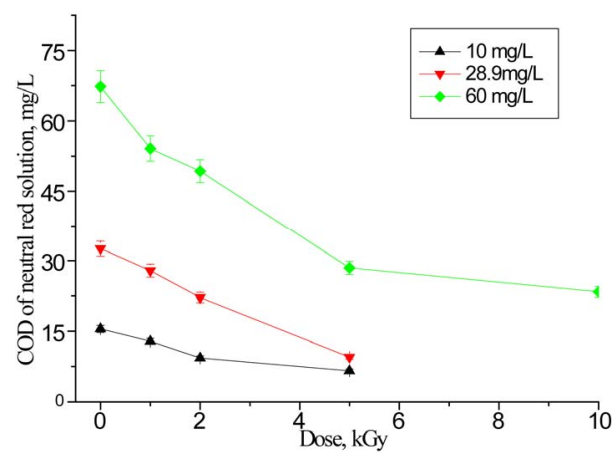

(b)

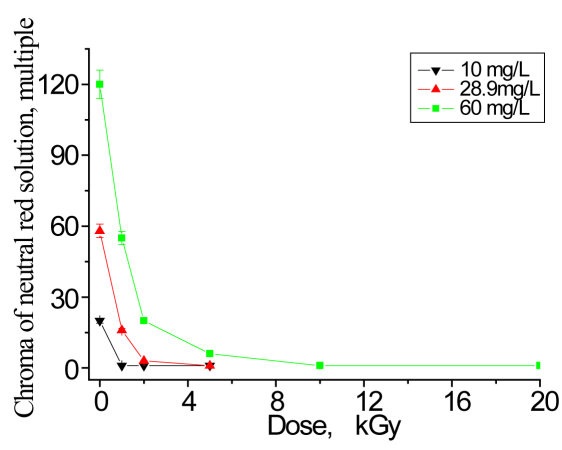

(c)

Figure 1. pH values (a), COD contents (b) and chroma (c) of the neutral red solutions under different absorbed doses. chroma of the neutral red solutions decreased more obviously with concentration increase. The chroma of neutral red solution decreased dramatically after irradiation. The color removed completely with an initial neutral red concentration of $10 \mathrm{mg} / \mathrm{L}$ at a dose of $1 \mathrm{kGy}$, an initial neutral red concentration of $28.9 \mathrm{mg} / \mathrm{L}$ at a dose of $5 \mathrm{kGy}$, an initial neutral red concentration of $60 \mathrm{mg} / \mathrm{L}$ at a dose of $10 \mathrm{kGy}$.

Figure 2 is the UV-Vis spectra of neutral red solutions. The absorbency data are normalized to the highest peak of $0 \mathrm{kGy}$ spectrum. The UV-Vis spectra illustrate that the main characteristic absorption peaks both at $266 \mathrm{~nm}$ and

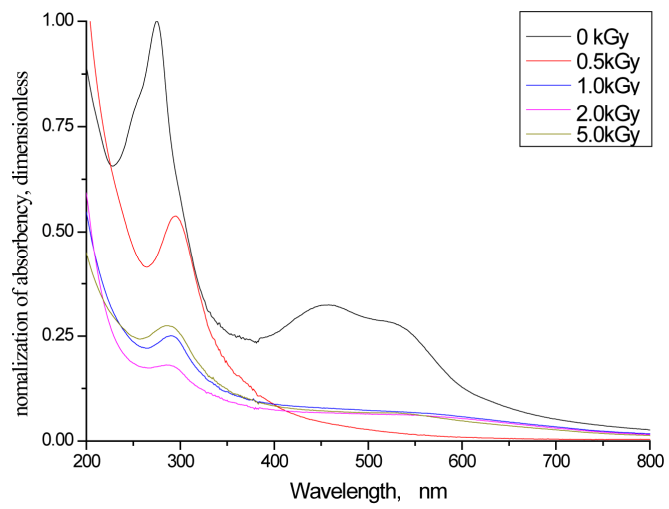

(a)

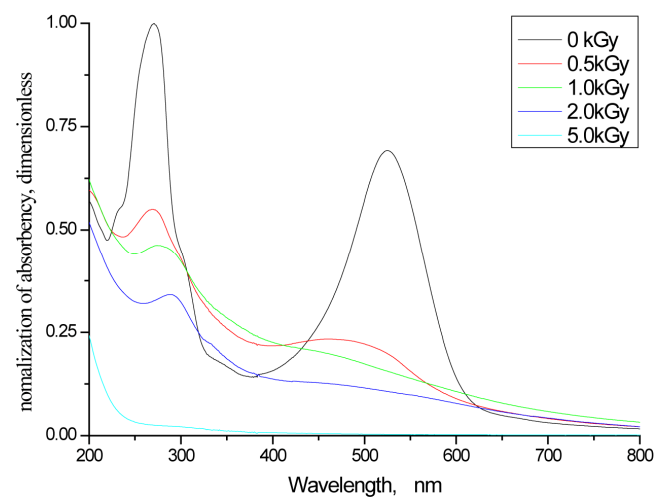

(b)

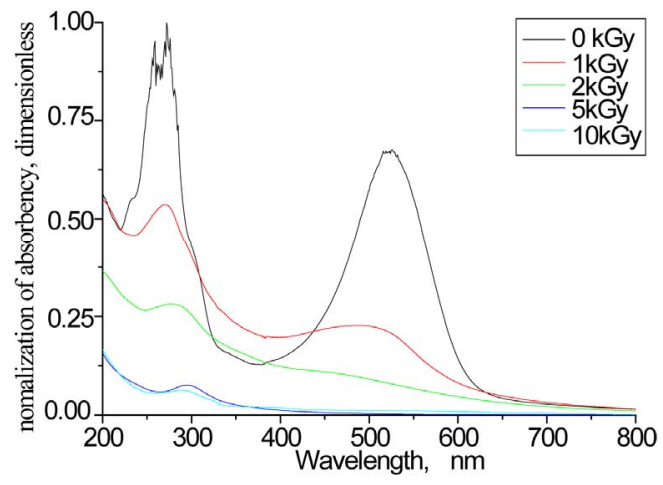

(c)

Figure 2. UV-Vis spectra of the neutral red solutions under different absorbed doses. 
$523 \mathrm{~nm}$ of neutral red disappeared basically for the an initial concentration of $10 \mathrm{mg} / \mathrm{L}$ at a dose of $1 \mathrm{kGy}$, initial concentration of $28.9 \mathrm{mg} / \mathrm{L}$ and $60 \mathrm{mg} / \mathrm{L}$ at a dose of $5 \mathrm{kGy}$. The absorbencies are close to zero.

\subsection{The Effect of Absorbed Dose Rate}

The neutral red solutions with concentration at $28.9 \mathrm{mg} / \mathrm{L}$ were irradiated for $5 \mathrm{kGy}$ at $4.51 \mathrm{~Gy} / \mathrm{min}, 8.90 \mathrm{~Gy} / \mathrm{min}$, 30.86 Gy/min, $61.73 \mathrm{~Gy} / \mathrm{min}$ and $86.91 \mathrm{~Gy} / \mathrm{min}$ respecttively. The $\mathrm{pH}$ values drop to from 5.86 before irradiation to $4.25 \sim 4.70$ after irradiation, which is shown in Figure 3(a). Although the acidity increased greatly, the $\mathrm{pH}$ values of the solutions irradiated at different dose rate are close to each other. The UV-vis absorptionspectra (in Figure 3(b)) of the same solutions irradiated at different dose rate are also identical. Both the $\mathrm{pH}$ values and $\mathrm{UV}$ vis absorptionspectra indicates that the absorbed doserate has little effect on the degradation efficiency of neutral red.

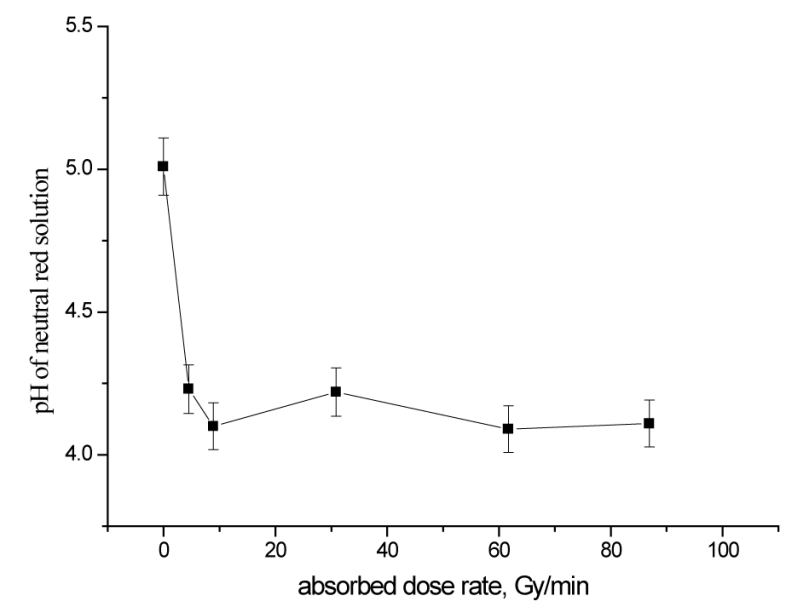

(a)

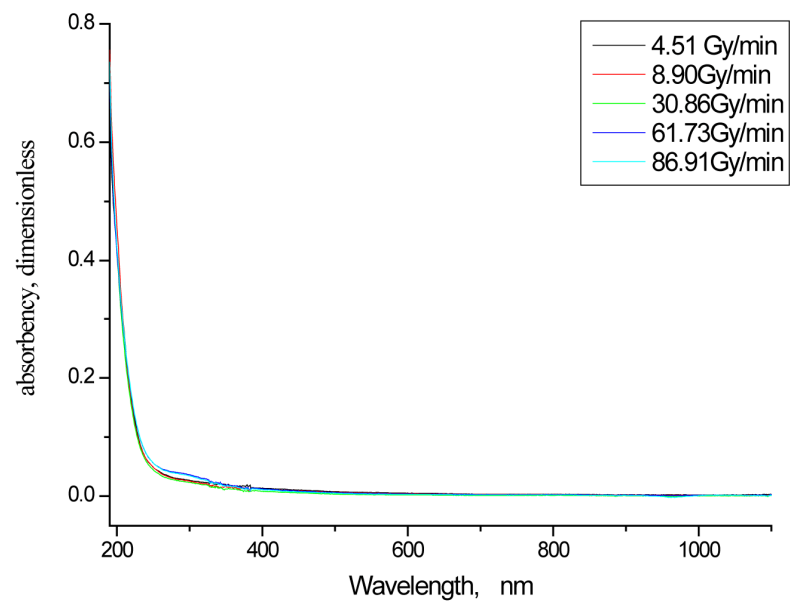

(b)

Figure 3. pH values (a) and UV-Vis spectra (b) of the neutral red solutions under different absorbed dose rates.

\subsection{The Effect of pH Value}

The neutral red solutions at $\mathrm{pH}$ values of $36.98,7.73$, 9.06 respectively were irradiated for $5 \mathrm{kGy}$ at 61.73 $\mathrm{Gy} / \mathrm{min}$. Their $\mathrm{pH}$ value changing is showed in Figure 4(a). The $\mathrm{pH}$ value changing is not obvious for acidic solutions but distinct for basic solutions. The studies in section 2.1 shows that there is at least an acidic compound produced during the radiation degradation of neutral red, the $\mathrm{pH}$ value of basic solutions decreased rapidly might because of acid-base neutralization.

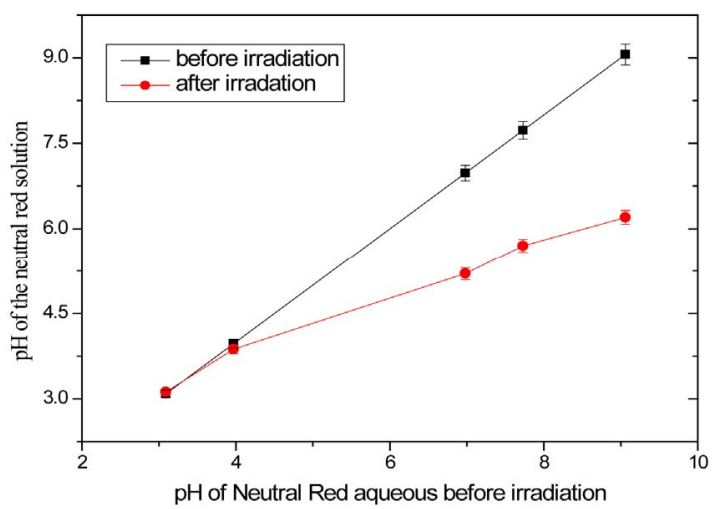

(a)

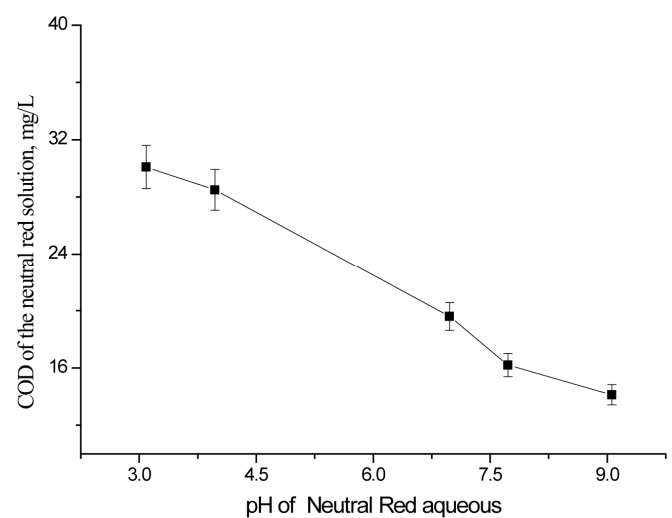

(b)

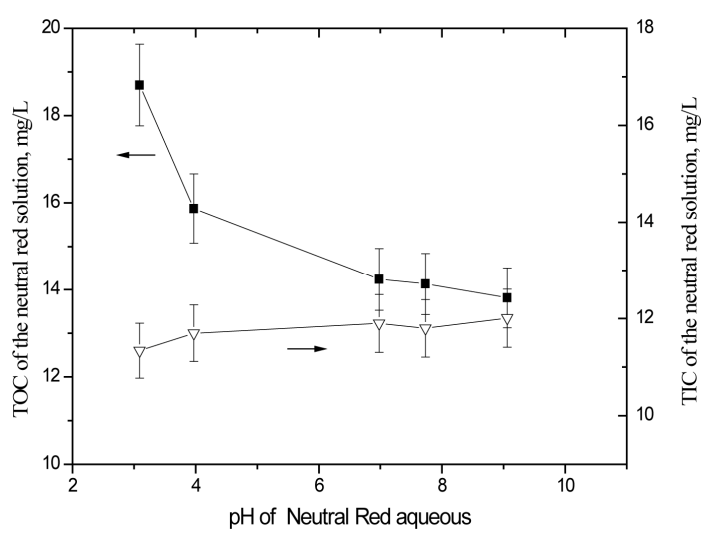

(c)

Figure 4. pH values (a), COD (b), TOC and TIC (c) of the neutral red solutions under different absorbed doses. 
The COD, TOC and TIC of neutral red solutions at various $\mathrm{pH}$ values were determined before and after irradiation, which are showed in Figures 4(b) and (c). The COD content of basic solution was less, indicating that alkalescency condition is propitious to the removal of COD. With the increase of alkalescence, TOC decreased obviously while TIC increase appreciably. The decrease of TOC reflects the mineralization of neutral red. While the increase of TIC is less than the decrease of TOC, and the TC content decreases gradually, indicating that some neutral red were degraded to carbon dioxide.

\subsection{The Effect of Hydrogen Peroxide}

Effect of $\mathrm{H}_{2} \mathrm{O}_{2}$ on the degradation of neutral red solution is evaluated by COD, pH determination (Figure 5) with the initial concentration of $0 \mathrm{mmol} / \mathrm{L}, 5.3 \mathrm{mmol} / \mathrm{L}, 8.9$ $\mathrm{mmol} / \mathrm{L}, 17.8 \mathrm{mmol} / \mathrm{L}, 35.5 \mathrm{mmol} / \mathrm{L}, 88.2 \mathrm{mmol} / \mathrm{L}$ and $174.8 \mathrm{mmol} / \mathrm{L}$. The concentration of neutral red solution is $60 \mathrm{mg} / \mathrm{L}$. Whether adding $\mathrm{H}_{2} \mathrm{O}_{2}$ in the neutral red solution or not, the $\mathrm{pH}$ value decreases after irradiation. And the $\mathrm{pH}$ value decreases more obviously after the addition of $\mathrm{H}_{2} \mathrm{O}_{2}$. The COD get lower with the $\mathrm{H}_{2} \mathrm{O}_{2}$ concentration of $5.3 \mathrm{mmol} / \mathrm{L}-35.5 \mathrm{mmol} / \mathrm{L}$. The addition of $\mathrm{H}_{2} \mathrm{O}_{2}$ enhanced the removal of COD. However, a further increase of $\mathrm{H}_{2} \mathrm{O}_{2}$ does not lead to further increase of COD removal when the concentration up to $88.2 \mathrm{mmol} / \mathrm{L}$. On the premise of the concentration of $\mathrm{H}_{2} \mathrm{O}_{2}$ greater than or equal to up to $88.2 \mathrm{mmol} / \mathrm{L}$, the COD of the neutral red solution increases with the increase of $\mathrm{H}_{2} \mathrm{O}_{2}$, but the chroma of the neutral red solutions does not increase. In the actual determination, the COD content of $49.0 \mathrm{mmol} / \mathrm{L}$ $\mathrm{H}_{2} \mathrm{O}_{2}$ prapared with ultrapure water is $68 \mathrm{mg} / \mathrm{L}$, indicating that the $\mathrm{H}_{2} \mathrm{O}_{2}$ has positive interference with the determination of COD. The $\mathrm{H}_{2} \mathrm{O}_{2}$ can produce oxygen under irradiation, and the oxygen can decompose organic compounds. Radiolysis occurs in the first place to produce some reactive primary species such as hydroxyl radicals $(\cdot \mathrm{OH})$, hydrogen atoms $(H \square)$, hydrated electrons $\left(e_{e q}^{-}\right)$ and hydrogen ions when the neutral red solutions are exposed to $\gamma$-ray [9]. Hydrated electrons can react with $\mathrm{H}_{2} \mathrm{O}_{2}$ to form $\cdot \mathrm{OH}$ and $\mathrm{OH}$

$$
\left(K=1.1 \times 10^{10} \mathrm{~L} \cdot \mathrm{mol}^{-1} \cdot \mathrm{s}^{-1}\right) .
$$

$H \square$ can react with $\mathrm{H}_{2} \mathrm{O}_{2}$ to form $\cdot \mathrm{OH}$ and $\mathrm{H}_{2} \mathrm{O} K=$ $\left(9 \times 10^{7} \mathrm{~L} \cdot \mathrm{mol}^{-1} \cdot \mathrm{s}^{-1}\right)[10]$. The $\cdot \mathrm{OH}$ has strong oxidation and can accelerate the decomposition of neutral red. But higher concentration $\mathrm{H}_{2} \mathrm{O}_{2}$ could not react completely. The remaining $\mathrm{H}_{2} \mathrm{O}_{2}$ cause interference with the determination of COD and make the COD larger.

\section{Conclusion}

The studies on the radiation degradation of neutral red solutions show that gamma-ray irradiation is an effective

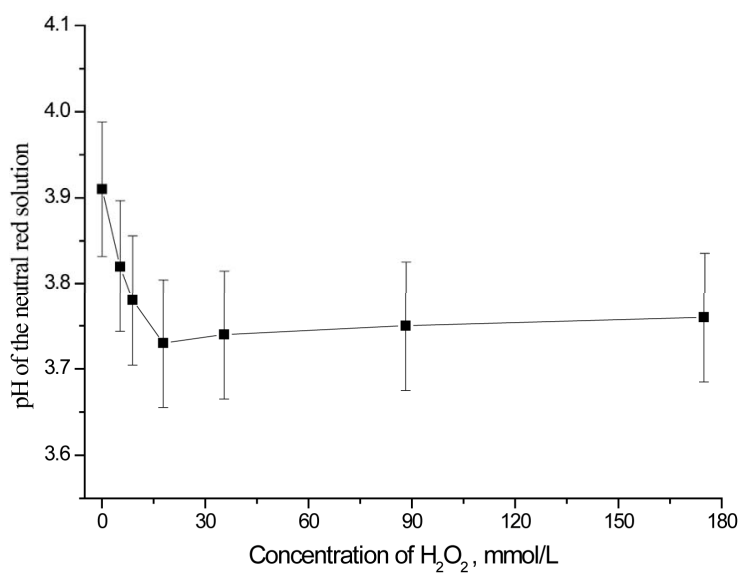

(a)

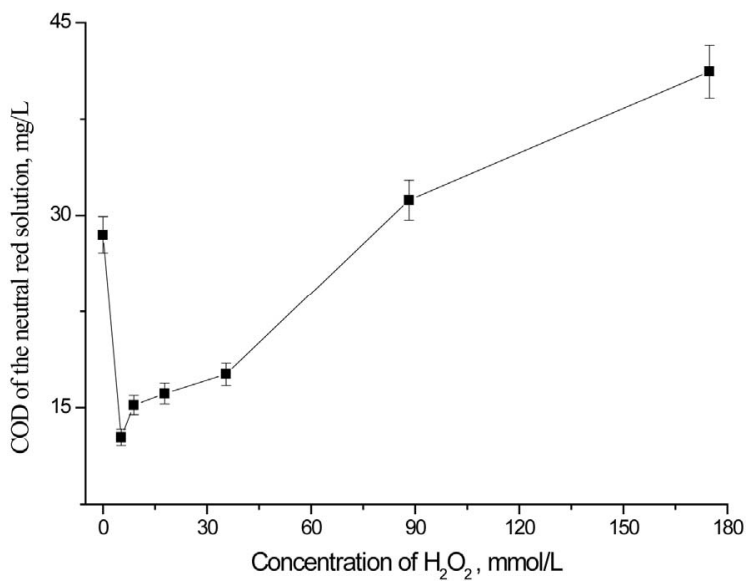

(b)

Figure 5. pH values (a) and COD contents (b) of the neutral red solutions with $\mathrm{H}_{2} \mathrm{O}_{2}$ existing.

method. The characteristic absorption peaks of neutral red disappeared basically and the absorbency are close to zero for the an initial concentration of $10 \mathrm{mg} / \mathrm{L}$ at a dose of $1 \mathrm{kGy}$, initial concentration of $28.9 \mathrm{mg} / \mathrm{L}$ and $60 \mathrm{mg} / \mathrm{L}$ at a dose of $5 \mathrm{kGy}$. With the increase of absorbed doses, the COD and chroma decreased conspicuously. The absorbed dose rate has little effect on the degradation of neutral red. When the absorbed doses are the same, with the increase of the concentration of neutral red between 0 $\mathrm{mg} / \mathrm{L}$ and $60 \mathrm{mg} / \mathrm{L}$, the COD and chroma decreased more obviously. Weak basic condition and proper $\mathrm{H}_{2} \mathrm{O}_{2}$ addiation are propitious to removal of COD of neutral red.

\section{Acknowledgements}

This work was financially supported by the Sichuan Provincial Science and technology program of China (Grant No. 2009GZ0037).

\section{REFERENCES}

[1] I. H. Faisal, Y. Kazuo and F. Kensuke, "Hybrid Treat- 
ment Systems for Dye Wastewater," Critical Reviews in Environmental Science and Technology, Vol. 37, No. 4, 2007, pp. 315-377. doi:10.1080/10643380601174723

[2] T. Polonca and I. Arcon, "Degradation of Organophosphorus Compounds by X-Ray Irradiation,” Radiation Physics and Chemistry, Vol. 67, No. 3-4, 2003, pp. 527530. doi:10.1016/S0969-806X(03)00099-9

[3] A. A. Basfar, K. A. Mohamed, A. J. Al-Abduly and A. A. Al-Shahrani, "Radiolytic Degradation of Atrazine Aqueous Solution Containing Humic Substances," Ecotoxicology and Environmental Safety, Vol. 72, No. 3, 2009, pp. 948-953. doi:10.1016/j.ecoenv.2008.05.006

[4] J. Choi, H. S. Lee, J. H. Kim, K. W. Lee, J. W. Lee, S. J. Seo, K. W. Kang and M. W. Byun, "Controlling the Radiation Degradation of Carboxymethylcellulose Solution, " Polymer Degradation and Stability, Vol. 93, No. 1, 2008, pp. 310-315. doi:10.1016/j.polymdegradstab.2007.10.014

[5] R. Zona, S. Solar and P. Gehringer, "Degradation of 2,4-Dichlorophenoxyacetic Acid by Ionizing Radiation: Influence of Oxygen Concentration," Water Research, Vol. 36, No. 5, 2002, pp. 1369-1374.

$$
\text { doi:10.1016/S0043-1354(01)00323-2 }
$$

[6] A. A. Basfar, H. M. Khan and A. A. Al-Shahrani, “Trihalomethane Treatment Using Gamma Irradiation: Kinetic Modeling of Single Solute and Mixture,” Radiation Physics and Chemistry, Vol. 72, No. 5, 2005, pp. 555563. doi:10.1016/j.radphyschem.2004.04.137

[7] E. A. Arbra [Former Soviet Union], "Industrial Electron Accelerators and Their Applications in Radiation Processing,” Atomic Energy Press, Beijing, 1990 (in Chinese).

[8] S. K. Huang, L. L. Hsieh, C. C. Chen, P. H. Lee and B. T. Hsieh, “A Study on Radiation Technological Degradation of Organic Chloride Wastewater-Exemplified by TCE and PCE," Applied Radiation and Isotopes, Vol. 67, No. 7-8, 2009, pp. 1493-1498. doi:10.1016/j.apradiso.2009.02.049

[9] J. W. T. Spinks and R. J. Woods, "Introduction to Radiation Chemistry,” Wiley Press, New York, 1990.

[10] M. Wang, R. Y. Yang, W. F. Wang, S. W. Bian and Z. Q. Shen, “ $\gamma$-Ray Induced Degradation of Reactive Blue KNR in Aqueous Solution,” Journal of Radiation Research and Radiation Processing, Vol. 22, No. 2, 2004, pp. $92-96$ (in Chinese). 